\title{
Simuladores Urbanos Digitais: Representação e Interação com a História das Cidades
}

\author{
Digital Urban Simulators: Representation and Interaction with the History of the Cities
}

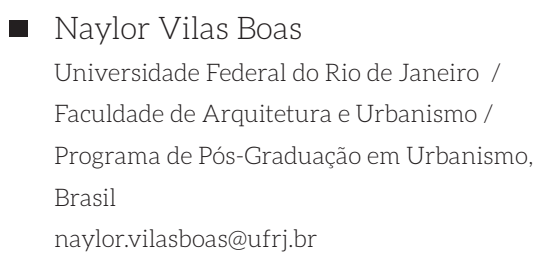

\begin{abstract}
This work aims to expose the methodological process of the construction of a digital urban simulator called "SIMRio", that is being developed at the Laboratory of Digital Representation and Urban Analysis. Constructed with the technology of videogames, through the use of its engines applied to digital $3 d$ models of central area of Rio de Janeiro, the research has the objective to develop interactive systems where one could virtually visit, in real time, not only the spaces of the city, but also different times of its history, walking between them as if were in a digital time machine.
\end{abstract}

Keywords: Rio de Janeiro, História, Videogames, Modelos Digitais

\section{Introdução}

Este artigo apresenta algumas reflexões acerca da trajetória metodológica de pesquisa e desenvolvimento do simulador urbano digital batizado de "SIMRio", elaborado a partir de tecnologias de construção de videogames, no Laboratório de Análise Urbana e Representação Digital (LAURD), do Programa de Pós-Graduação em Urbanismo da FAU/ UFRJ. Sendo um desdobramento da tese de doutorado do autor (Vilas Boas, 2007), que se debruçou sobre as questões epistemológicas relacionadas à inserção de modelos digitais urbanos em um contexto de pesquisa sobre a cidade e sua história, o SIMRio apresenta novos desafios metodológicos para a pesquisa em função de sua complexidade técnica, mas também aponta para a possibilidade de exploração de novas fronteiras da representação gráfica digital das cidades.

O SIMRio nasce como consequência direta da exploração das potencialidades dos modelos urbanos desenvolvidos inicialmente pelo LAURD em meados da década de 1990, cujo foco de interesse foi, e continua sendo, a área central do Rio de Janeiro. Alguns anos após sua elaboração inicial, e durante o desenvolvimento dos estudos de doutorado citados anteriormente, os modelos urbanos foram reformulados, quando se estabeleceu uma maior sustentação bibliográfica a partir de sua referenciação à clássica obra "Atlas da Evolução Histórica do Rio de Janeiro" (Canabrava, 1964), que permitiu a expansão dos modelos para diferentes momentos da história da cidade. Atualmente, os modelos, que representam uma área de $20 \mathrm{~km} 2$, estão sendo mais uma vez reformulados no sentido de uma melhor organização de sua complexa estrutura de informações, de modo a preparar sua utilização para as etapas futuras de desenvolvimento da pesquisa.

Desde o ano de 2012, uma abordagem relacionada à representação gráfica através da utilização das chamadas engines ou motores de videogames, que possibilitam a visualização dinâmica e a interação do usuário com o espaço digital, vem sendo desenvolvida utilizando os modelos urbanos do LAURD. Tais tecnologias representam não só uma das fronteiras atuais da Gráfica Digital, mas também um meio (e uma linguagem) cada vez mais naturalizada como um espaço de existência pessoal no mundo digital. Como já observava, ainda no início do século, o teórico Dennis Dollens (2002), "o espaço virtual, e em particular o espaço dos jogos, passaram a ser um território familiar, habitável, social e estético" (p. 18). Mais recentemente, Von Borries et al (2007) observa, em seu livro sobre a articulação entre Arquitetura e Videogames, que "os espaços digitais, tão frequentemente visitados pelos jogadores, mudaram e estão mudando nossa noção de espaço e tempo, do mesmo modo como o cinema e a televisão fizeram no século XX. (...) Os espaços dos jogos digitais, que se constituem pela convergência entre 'espaço', 'tempo' e a 'naarrativa', são somente o início' (p. 11).

No período de dois anos de pesquisa e desenvolvimento (2012-2014), foram produzidos três protótipos funcionais 
do SIMRio que, ao demonstrarem a exequibilidade do sistema, permitem uma visita ao espaço modelado do Largo da Carioca, no centro do Rio de Janeiro, no início do século $\mathrm{XX}$ e no início do século XXI. No entanto, o que torna o sistema particularmente interessante, em relação a outras experiências relacionadas à representação digital das cidades, é a possibilidade de transitar por estes dois tempos dinamicamente, alternando-os em tempo real. Com isso, trazse para a representação gráfica oferecida pelos motores dos videogames a possibilidade de visualizar as transformações da cidade a partir de uma perspectiva espaço-temporal, de uma maneira ainda não explorada pela historigrafia urbana.

\section{Os Videogames e as Cidades Digitais}

A emergência dos videogames como meio de entreterimento surge praticamente com o próprio computador e, junto com ele, se apresenta em constante evolução tecnológica. Ao longo do tempo, em uma relação "simbiótica", a capacidade gráfica dos computadores sempre determinou as possibilidades de representação dos videogames, ao mesmo tempo em que a demanda dos jogadores por representações cada vez mais complexas também sempre foi um fator de estímulo ao seu aprimoramento tecnológico.

Ao observarmos o desenvolvimento das representações dos espaços dos videogames sob uma perspectiva histórica, podemos observar uma contínua trajetória em direção à representação gráfica digital do espaço tridimensional (Boron, 2007), onde os avanços tecnológicos passaram gradativamente a permitir a imersão do jogador em um espaço onde pudesse atuar com liberdade total de movimento. É importante observar que, mesmo que atualmente a capacidade dos videogames já tenha alcançado tal objetivo, não foram invalidadas nem abandonadas as antigas abordagens. No atual contexto tecnológico, onde (quase) tudo é possível em termos de representação digital do espaço, as antigas limitações hoje se apresentam como diferentes possibilidades gráficas a serem utilizadas na programação de um videogame.

A questão da representação das cidades também se mostra presente desde os primeiros tempos. Por sua riqueza, tornam-se um meio natural para construções narrativas, que vem sendo explorado por diversas experiências dignas de nota (Paraízo, 2014), sejam através de simulações de planejamento urbano (como o clássico jogo SimCity); sejam em aventuras passadas em cidades contemporâneas (como a série Grand Theft Auto), ou em cidades do passado (como a série Assassin's Creed).

Tanto quanto a própria capacidade gráfica dos videogames evoluiu através do estímulo à evolução técnica dos computadores, o mesmo pode ser dito da representação do ambiente urbano. A complexidade natural das cidades sempre representou enormes desafios à sua representação através do computador. Traçando esta trajetória, Paraízo (2014) observa que "a cidade bidimensional dos primeiros jogos de computador é labiríntica, quando vista de cima, ou um cenário de fundo, em vista lateral (...). Quando é usada a perspectiva central de um ponto de fuga, caso de diversos jogos de corrida, a cidade, quando surge, permanece inalcançável ao fundo. (...) Os primeiros jogos tridimensionais faziam do labirinto uma forma conveniente de bloquear a visão do jogador, tanto porque o labirinto é um tema recorrente nos jogos quanto pela economia de processamento gerada pela visão obstruída resultante da ambientação em lugares fechados".

Atualmente, tal questão parece superada, na medida em que títulos recentes já apresentam representações doambiente urbano com um nível de detalhamento impressionante, impraticáveis tecnicamente mesmo há poucos anos atrás. Para termos uma ideia, dentre aqueles já citados, a última edição do Grand Theft Auto (GTA V) reproduz uma cidade habitada, em pleno funcionamento, com uma área urbana de aproximadamente $32 \mathrm{~km} 2$, por sua vez inserida em uma ilha de 147km2; enquanto que a série Assassin's Creed tornou-se famosa por suas incríveis reproduções, igualmente habitadas, de icônicas cidades do passado, como Florença e Veneza renascentistas e, mais recentemente, da Londres vitoriana.

Mesmo com todos esses avanços tecnológicos em termos quantitativos nas representações digitais das cidades (áreas mais extensas, mais detalhes, mais efeitos, e assim por diante), os videogames ainda não exploraram significativamente outras qualidades do espaço, que neles continua sendo fundamentalmente euclidiano, estático, um repositório neutro das ações que nele acontecem. O tipo de concepção de espaço concebido inicialmente na arte renascentista, contruído cientificamente por Galileu e, posteriormente, estruturado matematicamente por Newton. Segundo Werthein (2001), "para [Galileu], 'o mundo real [era] um mundo de corpos que se moviam no espaço e no tempo'. Tudo o mais - todas as ricas qualidades sensuais, como cores, cheiros, gostos e sons - devia ser agora considerado meramente secundário, subprodutos da 'verdadeira' realidade, que era matéria em movimento num espaço vazio" (p.88).

Apesar de já ter sido superado pelas ideias relativísticas de Einstein no início do século XX, que definem o tempo como um dos seus elementos fundamentais (o espaço-tempo), a concepção clássica do espaço ainda domina o senso comum, mesmo nas atuais fronteiras de exploração da representação gráfica digital. É o que se observa no âmbito dos videogames, especificamente naqueles que mais se aproximam de uma representação "realista" da cidade. Isso implica em que, apesar das cidades digitais estarem cada vez mais detalhadas em sua representação gráfica, ainda não trazem, imanente à sua estrutura construtiva básica, a perspectiva de sua transformação no tempo.

Para nossos atuais objetivos de pesquisa sobre as transformações urbanas do Rio de Janeiro através da exploração de tais tecnologias, essa éuma questão fundamental a ser enfrentada.

\section{Os Modelos Urbanos Digitais do LAURD}

A trajetória de pesquisa do LAURD, desde sua criação 
em 1995, é identificada em grande parte pela utilização de modelos digitais como objeto de construção de conhecimento sobre a arquitetura e sobre a cidade. Em diferentes trabalhos desenvolvidos pelo grupo ao longo dos anos, os modelos tiveram um importante papel de condutores e estruturadores dos estudos, não só como meios de representação mas também como intrumentos de pesquisa. Em sua trajetória de duas décadas, o laboratório conseguiu construir e consolidar um corpo de conhecimento relacionado às questões teóricometodológicas de sua utilização como instrumento de pesquisa urbana (Segre, 2010; Vilas Boas, 2010) que continua sendo sistematicamente aplicado, e também aprimorado, no desenvolvimento dos estudos do grupo.

No LAURD, a preocupação com a representação da cidade através da modelagem digital começou com o desenvolvimento de um estudo elaborado no ano de 1997 , quando o laboratório desenvolveu um sistema multimídia sobre a cidade de Havana Colonial (Kós \& Paraízo, 2007). Posteriormente, em 1999, as experiências adquiridas naquele momento foram aplicadas em um estudo similar sobre o Rio de Janeiro Colonial (Kós, 2001). Na ocasião, um modelo digital do centro da cidade colonial, incluindo a representação de sua complexa topografia e de edifícios importantes, foi desenvolvido, em um esforço "heróico" dada a complexidade da tarefa e as limitações técnicas existentes na época.

É importante observar que, nesse estudo, o modelo digital foi utilizado como base da narrativa sobre a história da cidade, onde as informações textuais e iconográficas se subordinavam a ele na estruturação gráfica do aplicativo. Desse modo, o modelo digital (mais precisamente, suas imagens renderizadas) conduziam o processo narrativo e espacializavam as informações sobre a cidade colonial.

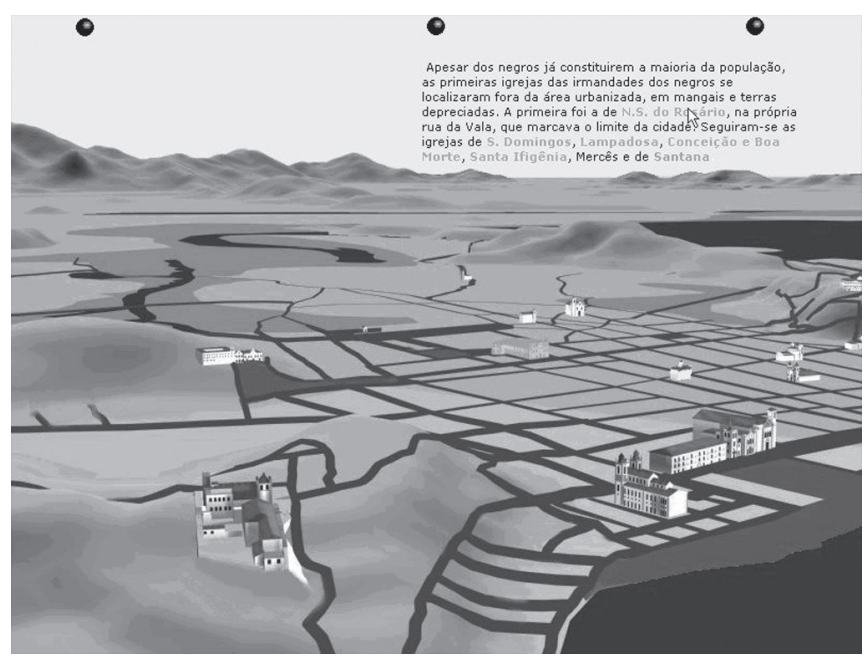

Figura 1: Rio Colonial: uma das primeiras experiências do LAURD com modelos urbanos digitais.

Este primeiro modelo urbano feito pelo LAURD estabeleceu as bases para o desenvolvimento dos modelos em uso atualmente, elaborados a partir das informações contidas na obra de Eduardo Canabrava (Canabrava, 1964).
Ainda que a representação gráfica dos mapas contidos em seu atlas não apresentassem a qualidade de trabalhos mais recentes, que também produzem uma cartografia histórica autoral (Andreatta, 2008), a maneira como as informações são organizadas e articuladas fazem de seu trabalho uma fonte fundamental para pesquisas sobre o crescimento da cidade.

O atlas contém pranchas que representam as características básicas do centro nos anos de 1600, 1650, 1713, $1750,1808,1850,1910,1928,1946$ e 1964, bem como relaciona textualmente o surgimento e as transformações, ao longo destas datas, de elementos urbanos de diferentes naturezas: a construção e demolição de edifícios significativos, a abertura de ruas e as modificações no meio natural, como o aterramento de áreas alagadas e o arrasamento de morros.

Em um primeira reformulação dos modelos urbanos do LAURD, ocorrida por voltadoanode2002, asinformaçõescontidas no atlas foram tridimensionalizadas através da modelagem digital (o modelo do ano 2000 foi feito a partir de bases cadastrais atuais, já que o estudo do atlas se conclui no ano de 1964, ano de sua publicação), sendo que os edifícios foram aproveitados do modelo utilizado na construção do Rio Colonial. Neste processo, a obra de Canabrava adquiriu novas potencialidades, visto que sua versão digital passou a lhe conferir atributos próprios do novo meio, ampliando suas qualidades documentais.

Expansões e detalhamentos subsequentes foram feitos nos modelos, principalmente durante a pesquisa sobre o edifício do Ministério da Educação e Saúde (2000-2005), que originou um complexo sistema multimídia sobre a obra e que, por sua vez, deu origem ao mais completo livro sobre o edifício já publicado (Segre, 2013). Durante essa pesquisa, os modelos digitais, da cidade ou do proprio edifício, mostraram-se instrumentos fundamentais de construção de conhecimento.

Posteriormente, para os estudos de doutorado do autor (2004-2007), outras partes do modelo foram detalhadas, principalmente a área do antigo Morro do Castelo em 1910, cujo processo de arrasamento foi estudado através da modelagem digital. Mais recentemente, outras partes dos modelos foram detalhadas para o desenvolvimento dos protótipos do SIMRio, especificamente a área do Largo da Carioca em seu aspecto atual e também em 1910.

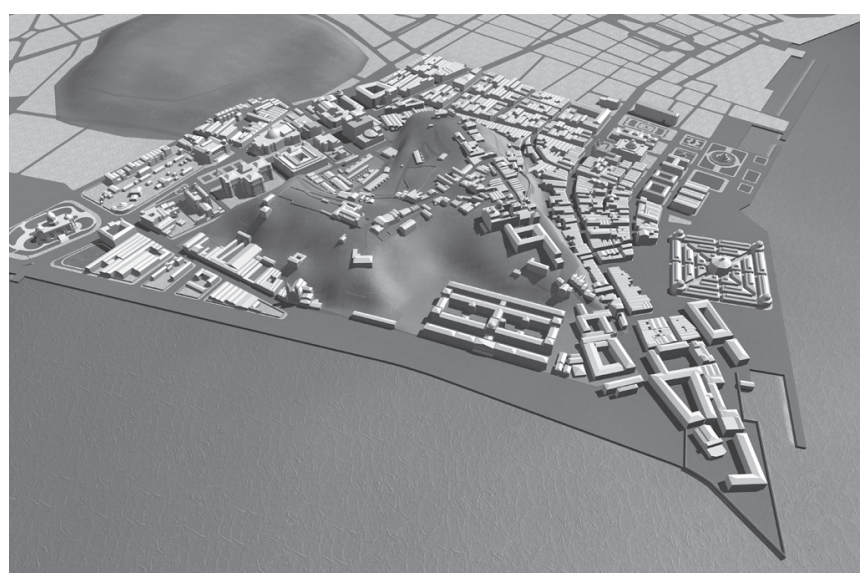

Figura 2: Modelo digital do Morro do Castelo e seu entorno em 1910. 
Após todos estes estudos, observou-se a necessidade de uma nova reformulação dos modelos urbanos do LAURD, tendo em vista a fragmentação ocorrida durante anos de utilização que fizeram o conjunto original se perder. É nesse sentido que os modelos estão sendo reformulados, incorporando aprimoramentos necessários para dar o suporte metodológico para as próximas etapas das pesquisas..

\section{Caminhos Metodológicos do SIMRio}

\section{Antecedentes}

As origens específicas do SIMRio estão localizadas no estudo sobre o Morro do Castelo, objeto da tese de doutorado citada anteriormente. Na ocasião, um trecho do modelo urbano do LAURD, que representava a cidade no ano de 1910 e no ano 2000 , foram separados do conjunto original e utilizados como ferramentas autônomas de pesquisa. A partir da incorporação de plantas cadastrais e fotos aéreas originais, que descreviam a área com maior nível de detalhes na década de 1910, o modelo foi sendo gradativamente detalhado, principalmente em relação à topografia do Morro do Castelo e de todo o casario do próprio morro e de seu entorno, descrevendo uma área de $4 \mathrm{~km} 2$ de grande importância.

Foram derivados uma série de outros que descreviam momentos intermediários do arrasamento do morro, além de modelos dos vários projetos propostos para área, referenciados na documentação primária utilizada durante a pesquisa. Em função da proposta do estudo, que abrangia uma área onde grandes transformações haviam ocorrido no início do século $\mathrm{XX}$, seu desenvolvimento não foi além da escala urbana de representação (Vilas Boas, 2010), o que permitiu um olhar mais geral e sistêmico sobre ela.

A utlização de documentação detalhada que representava a área do morro ampliou a consistência destes modelos urbanos como documentos efetivos de pesquisa. Com o aumento da precisão na descrição de um trecho da cidade no início do século XX, a pesquisa avançou no sentido de uma aproximação do olhar sobre a área. Para tal fim, uma mudança de escala de representação do modelo começou a ser implementada, e a escala arquitetônica (Vilas Boas, 2010) passou a definir seus rumos de desenvolvimento.

Como resultados parciais desse processo, estudos voltados para as características sociais do morro, especificamente para a identificação, através do modelo digital, dos seus espaços urbanos, bem como dos moradores e suas casas, foram produzidos a partir do cruzamento de um modelo agora mais detalhado e informações extraídas de antigos catálogos telefônicos (Jornada, 2010), Também através do modelo, foi possível reconstituir visualmente a subida das personagens Natividade e Perpétua ao Morro do Castelo, narrado por Machado de Assis na obra "Esaú e Jacó" (Jornada, 2010).

As possibilidades de visualização (e entendimento) que se abriram com a aproximação do olhar, permitida pela ampliação para a escala arquitetônica de determinadas áreas dos modelos de certa forma estabeleceram as condições para a inserção dos motores gráficos dos videogames como uma ferramenta efetiva de pesquisa.

É importante observar que tais possibilidades já haviam sido testadas, com alguns resultados, ainda no início dos estudos de doutorado, através da ferramenta Blender, um modelador digital de código aberto, que contém em um de seus módulos um motor gráfico específico. Na ocasião, a questão teórica centrava-se na natureza do movimento no espaço tridimensional que tais tecnologias permitem, cuja representação é fundamentalmente diferente das animações gráficas pré-definidas, sendo que a preocupação com a representação dos tempos da cidade ainda não estava colocada. (Vilas Boas, 2005). Posteriormente, os caminhos da tese seguiram para o problema da modelagem em si, e a experiência com os motores gráficos foram deixadas de lado.

A retomada dessa linha de trabalho estabeleceu novas demandas, visto que sua complexidade técnica, e também suas potencialidades, passaram a justificar uma reestruturação nos modelos digitais urbanos do LAURD e dos processos teóricometodológicos a eles associados.

\section{A produção dos protótipos}

Foram construídos três protótipos do simulador urbano SIMRio, que tem como objetivo permitir a visualização das transformações espaciais do Largo da Carioca, no centro do Rio de Janeiro, no intervalo de cem anos de sua história. A escolha deste espaço urbano se deu em função do deslocamento do eixo da pesquisa, a partir de 2011, da área do Morro do Castelo para a área do Morro de Santo Antônio, para convergir os esforços de trabalho da equipe com outro estudo que começava a ser feito pelo professor Roberto Segre com sua equipe de estudantes de Iniciação Científica.

Em uma primeira abordagem ao novo espaço estudado, começou-se a detalhar na escala arquitetônica, através da articulação de mapas históricos do final do século XIX e análise de outras documentações, o casario da tradicional Rua da Carioca, bem como os edifícios e outros elementos urbanos do antigo largo, hoje desaparecidos, como o Chafariz da Carioca e o edifício do Hospital da Ordem Terceira da Penintência, demolidos nos primeiros anos do século XX. O passo seguinte foi o detalhamento do conjunto da acrópole religiosa do Morro de Santo Antônio, que também constitui parte fundamental da paisagem do Largo da Carioca.

Os resultados obtidos nessa etapa da pesquisa, não só pela produção de modelos digitais detalhados, mas principalmente pelo entendimento das dinâmicas de transformação da área que eles permitiram visualizar, abriu a oportunidade de incoporar um primeiro motor gráfico - o Unity - de maneira consistente à pesquisa, utilizado para produzir a versão 0.1 do SIMRio. A escolha do Unity se deu principalmente pelo fato de ser uma ferramenta gratuita, com facilidade de uso e que permite fácil importação dos modelos feitos em outros programas, além de ter uma comunidade bastante ativa, o que facilita o seu processo de aprendizado. (Jornada, 2013).

A primeira versão do SIMRio pode ser entendido como 
uma prova de conceito bem sucedida, que demonstra a possibilidade técnica de sobrepor dois modelos urbanos distintos e alternar a sua visualização em tempo real, pelo menos no Unity. Apesar do foco do estudo ter sido o Largo da Carioca, foram utilizados os modelos do LAURD em sua extensão original, que permite a ida a outras áreas do centro (como o Morro do Castelo, por exemplo), ainda que boa parte dos edifícios fossem modelados na escala urbana, não fornecendo uma reposta visual satisfatória ao observador próximo a eles. A alternância temporal também funciona a contento, ainda que sem a fluidez necessária para uma transição visual mais suave.

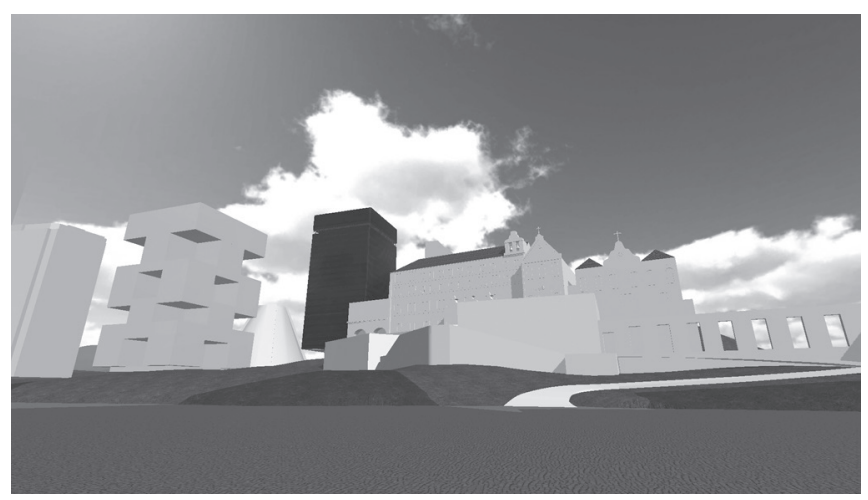

Figura 3: O Largo da Carioca no ano 2000 na versão 0.1 do SIMRio.

Após as avaliações dos resultados desta primeira experiência, outro motor gráfico foi testado como alternativa às limitações observadas no Unity, principalmente em relação à sua capacidade de lidar com modelos digtais detalhados muito grandes e à capacidade gráfica limitada da ferramenta (Jornada, 2013)..

Nesse sentido, migrou-se para o motor gráfico chamado de UDK, abreviação de Unreal Development Kit, poderosa ferramenta desenvolvida para a construção do jogo Unreal, e disponibilizada gratuitamente para qualquer desenvolvedor interessado em construir seus próprios videogames, que somente pagará por ela se sua produção for bem sucedida financeiramente. No caso de uma pesquisa acadêmica sem fins lucrativos, seu uso é gratuito. Ainda que seja uma ferramenta mais complexa e de difícil aprendizado, suas capacidades de representação gráfica mais amplas justificaram esta escolha (Jornada, 2013). Com o motor gráfico UDK foram construídos as versões 0.2 e 0.3 do SIMRio, sendo que só a versão 0.2 permite a transição temporal, que não foi implementada na última em função de desmobilização da equipe para viagens de intercâmbio.

A inserção desta nova ferramenta na pesquisa, bem como os objetivos definidos - a construção do Largo da Carioca naqueles dois momentos de sua história, complexificou substancialmente os trabalhos da pesquisa. Em seu momento de maior desenvolvimento, no ano de 2013, uma equipe multidisciplinar de dez alunos de Iniciação Científica estavam envolvidos em sua produção, divididos em grupos responsáveis pelo cumprimento de determinadas tarefas.

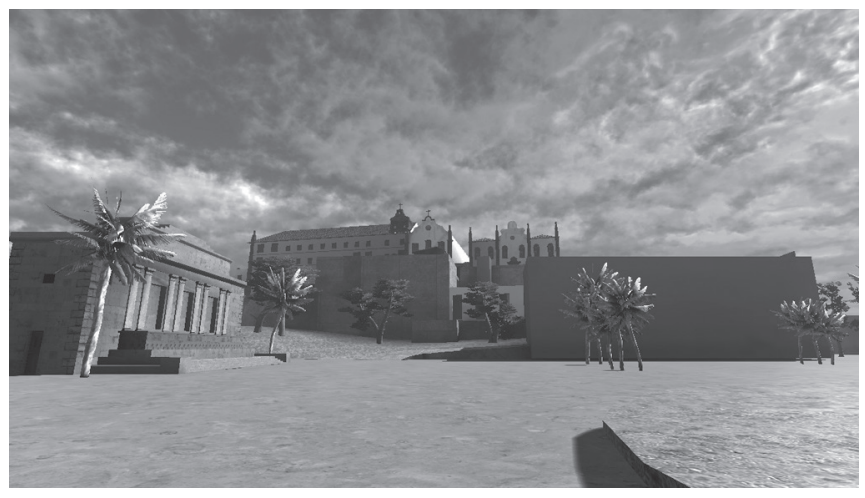

Figura 4: O Largo da Carioca no ano de 1910 na versão 0.2 do SIMRio.

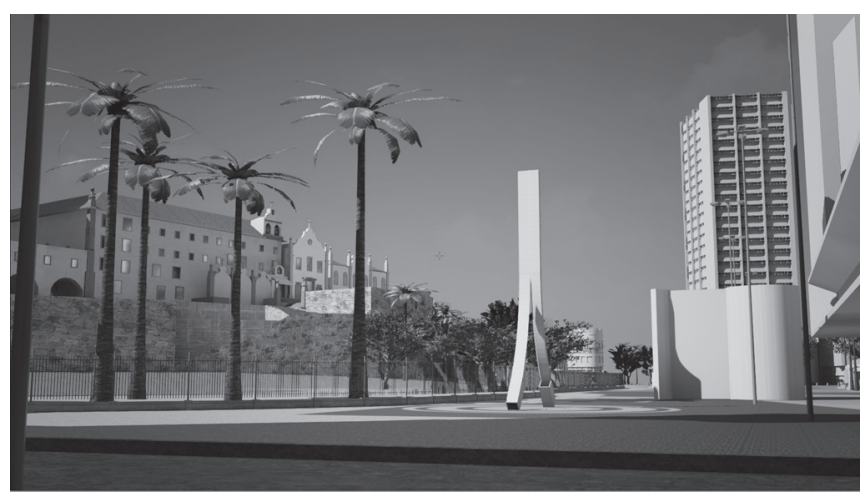

Figura 5: O Largo da Carioca no ano 2000 na versão 0.3 do SIMRio.

\section{Abordagens disciplinares}

Para a versão 0.3 do SIMRio, um fluxo de trabalho de produção gráfica digital necessário para a construção do simulador foi definido, e as diferentes etapas de sua estrutura foram atribuídas aos alunos que mais se identificavam com a natureza do trabalho a ser feito. Relacionamos abaixo as suas principais etapas, que não devem ser entendidas de modo linear, mas como linhas independentes e complementares, que se articulam em torno do motor gráfico.

\section{Construção da plataforma}

Aqui é o lugar de motor gráfico utilizado para a construção final do simulador, lugar de síntese de todas as linhas de trabalho que se desdobram a partir dos objetivos propostos. É no motor gráfico que serão reunidos e articulados todos os modelos digitais produzidos, e também implementadas uma série de outras funcionalidades, somente possíveis em seu ambiente, como a própria movimentação no espaço e no tempo, além de elementos de importância secundária, como efeitos sonoros, população, modelagem do clima e do ciclo de dias e noites, entre outras possibilidades.

É importante observar que o conhecimento técnico desta ferramenta é estratégico para o desenvolvimento da pesquisa, seja qual for o motor gráfico escolhido. Considerando a 
transitoriedade dos alunos nos grupos de pesquisa na Iniciação Científica, é fundamental que o orientador tenha o conhecimento básico de seu funcionamento, suficiente para permitir a formação inicial de novos alunos que ingressam, para que o desenvolvimento da sua principal linha de trabalho não seja interrompida.

\section{Modelagem digital de edifícios existentes}

A modelagem dos edifícios na escala arquitetônica, para o detalhamento do modelo urbano que descreve a cidade atual, não apresenta maiores desafios metodológicos. No entanto, implica em um aprofundamento na observação direta da cidade por parte dos alunos, a partir de visitas fotográficas e elaboração de croquis de observação dos edifícios a serem modelados. Esse contato direto permite a percepção das qualidades urbanas do local de implantação de cada edfício que será modelado, perspectiva que não deve ser perdida entre aqueles envolvidos na produção de um simulador urbano.

\section{Modelagem digital de edifícios não-existentes}

Apesar de tratar-se também de modelagem de edifícios, a abordagem necessária para lidar com aqueles já demolidos é muito diferente da utilizada para os edifícios ainda existentes. Mesmo neste caso, onde o contato direto com o edfício não é possível, a vivência direta com a cidade e o lugar onde ele se implantava continua sendo fundamental. Ainda assim, é uma linha de trabalho ligada à pesquisas em acervos e análise de documentação iconográfica que descrevem os edifícios a serem modelados. É um trabalho de investigação em laboratório, onde o pesquisador vai lidar com cruzamento de informações, modelar hipóteses sobre a forma dos edifícos, e ter um contato mais direto com o passado da cidade.

A modelagem destes edifícios também apresenta dificuldades adicionais, em função do seu próprio estilo arquitetônico, representativos de uma cidade fundamentalmente eclética. Profusões de detalhes arquitetônicos povoam suas fachadas, e estratégias específicas para o detalhamento do modelo devem ser consideradas, em função das limitações dos próprios motores gráficos em lidar

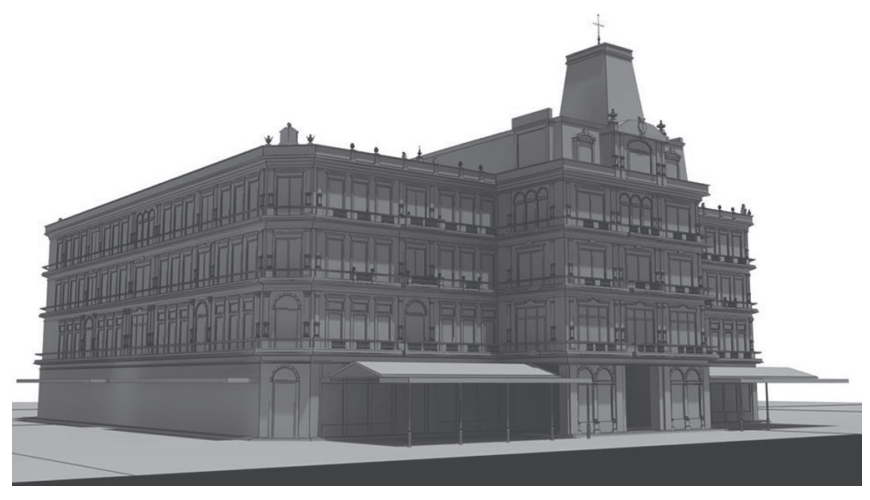

Figura 6: Modelo digital do antigo Hotel Avenida, grande edifício eclético do centro do Rio demolido na década de 1950. com um grande volume de informações, se considerarmos a representação de todo um conjunto urbano eclético.

\section{Modelagem do Mobiliário Urbano}

Esta é uma etapa de grande importância para a qualidade visual do simulador, e diz respeito à representação dos objetos de pequena escala da cidade. Mais do que o detalhamento arquitetônico dos modelos dos edifícios, são esses pequenos elementos da paisagem urbana - postes, telefones públicos, sinais de trânsito, bancas de jornal - que possibilitam uma resposta visual satisfatória aos passeios feitos no simulador.

De uma maneira geral, a mesma lógica relacionada aos edifícios se aplica. No entanto, a modelagem destes elementos no passado acrescenta um desafio a mais em função da sua pequena escala, que dificulta as análises nas fotografias (quase nunca são o próprio objeto da foto) e na rara documentação existente sobre eles.

No caso do SIMRio, essa etapa representou um ponto de contato interdisciplinar importante, na medida em que incorporou um levantamento espacial e fotográfico dos elementos atuais do mobiliário urbano do Largo da Carioca, elaborado para uma tese de doutorado desenvolvida no âmbito do LAURD, cujo tema estava relacionado com a paisagem gráfica da cidade (Till, 2014).

Pelo fato do Largo da Carioca no passado não ter sido desenvolvido na versão 0.3 , não foi possível avançar pelo caminho do seu mobiliário urbano. Antigos elementos ainda existentes - como o icônico relógio da Carioca - foram modelados a partir de levantamentos e observações atuais, e serão aproveitados futuramente para esses modelos urbanos.

\section{Modelagem da topografia}

A topografia do centro do Rio de Janeiro não é formada por elementos fixos no tempo de vida de uma cidade. Por suas características naturais, a área central sempre foi terreno para grandes transformações da paisagem, na medida em era necessário aterrar áreas alagadiças e derrubar morros a fim de ganhar terreno para o seu crescimento. Nesse contexto, também sua representação através da modelagem digital deve considerar essa característica específica da cidade.

Abordagens metodológicas para lidar com essa questão através dos modelos digitais foram sistematizadas e bem documentadas no estudo sobre o Morro do Castelo (Vilas Boas, 2007), e vem sendo aplicadas desde então. No âmbito do SIMRio, os esforços se concentraram na atualização da descrição bidimensional da topografia (geratrizes dos modelos tridimensionais) a partir de bases cadastrais digitais contemporâneas, já que na obra de Canabrava, a qual estavam referenciadas anteriormente não estão representadas satisfatoriamente, e geravam modelos bastante imprecisos em relação aos aspectos reais da topografia da área central.

\section{Pesquisa histórica}

Esta etapa também representou um ponto de contato interdisciplinar, neste caso, relacionado à pesquisa que estava 
sendo desenvolvida pelo Professor Roberto Segre sobre o Morro de Santo Antônio, que deu origem a uma série de artigos sobre suas dinâmicas históricas (Segre et al, 2012a), propostas de projeto (Segre e Vilas Boas, 2011) e o processo de arrasamento (Segre et al, 2012b).

Essa pesquisa foi muito similar à relacionada com o Morro do Castelo, onde uma grande quantidade de documentação iconográfica histórica foi organizada e sistematizada. Ainda que não tenham sido centrais para o desenvolvimento dos protótipos do SIMRio, as informações organizadas pelos integrantes dessa pesquisa, alunos de Iniciação Científica sob orientação do Professor Segre, contribuíram para a contextualização histórica da área e como uma fonte de consulta sistematizada para os alunos e pesquisadores envolvidos na produção do simulador.

\section{Programação}

A programação necessária para o funcionamento do simulador urbano é um ponto importante de ser observado, visto que de todas as áreas disciplinares envolvidas, essa é a que mais se afasta dos campos da representação gráfica digital e do urbanismo. Nesse sentido, a participação de alunos de outras escolas, mais especificamente aquelas ligadas às ciências da computação, informática, matemática e afins torna-se fundamental para o seu desenvolvimento.

De qualquer modo, também um conhecimento básico das lógicas de programação deve ser de domínio dos alunos de Arquitetura diretamente ligados à construção da plataforma. Esse aprendizado, mesmo empírico, vem sendo facilitado pela adoção de interfaces gráficas de ordenação lógica e visual da própria programação, não só pelos motores gráficos, mas também por ferramentas de modelagem como o 3d Studio MAX e o Grasshopper (esse mais voltado para aplicações de fabricação digital),

\section{Desdobramentos e Possibilidades}

Apósa desmobilização da equipe, odesenvolvimentodesta etapa do SIMRio foi concluído em relação à implementação das informações dos modelos digitais no motor gráfico UDK. A partir das experiências adquiridas, as reflexões presentes neste artigo puderam ser organizadas, para que possam estruturar metodologicamente os passos seguintes..

No momento atual (2014-2015), uma grande reestruturação dos modelos urbanos digitais do LAURD vem sendo conduzida, a fim de que o conjunto original das bases gráficas possam ser devidamente reconstituídos e aprimorados. Em uma primeira abordagem, as bases bidimensionais vetoriais dos diferentes tempos estão sendo revistas, otimizadas e compatibilizadas entre si, em arquivos .cdr (CorelDraw). Através da versatilidade (Vilas Boas, 2007, p. 50), estas bases podem, por si só, gerar resultados específicos, como os mapas históricos elaborados recentemente para um livro sobre a história do Largo da Misericórdia (Sillos, 2015).

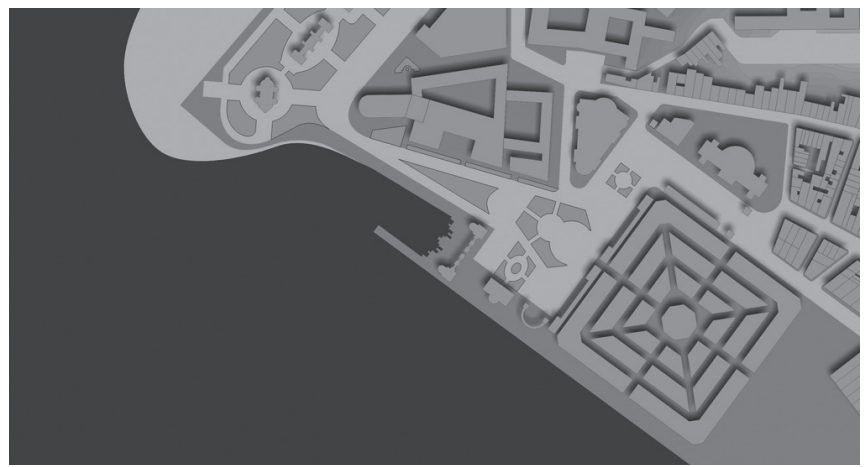

Figura 7: Mapa do Largo da Misericórdia em 1922 como subproduto dos modelos bidimensionais.

As bases bidimensionais são as geratrizes dos modelos tridimensionais, local onde os conflitos de compatibilidade das diferentes fontes documentais deve ser em boa parte resolvido, antes da sua tridimensionalização. Nesse sentido, devem ser entendidos como modelos bidimensionais da cidade. Na dissertação de mestrado sobre globos virtuais, Bueno (2013) demonstra a dificuldade na compatilização da documentação gráfica (plantas, projetos etc), feitas ao longo dos anos sobre o Morro de Santo Antônio.

Tal dificuldade de compatibilização, quando não a sua impossibilidade, abre espaço para alguma margem de interpretação do pesquisador que constrói os modelos bidimensionais a partir do cruzamento de diferentes documentos. Nesse sentido, torna-se mais importante garantir a correspondência das informações, nos limites da possibilidade de seu reconhecimento, do que a reprodução exata das informações de um meio no outro. De certa forma, essa síntese de várias fontes em um único documento digital, cujas imprecisões são a ele incroporadas dentro de uma margem de erro aceitável, é entendida por Chartier (1990) como o "consumo cultural", o processo de interpretação de uma documentação histórica pelas ferramentas disponíveis de cada época que se debruça sobre ela.

Uma implementação importante nesta nova versão dos modelos bidimensionais é o estabelecimento de uma grade sobre ele, que vai permitir a modulação do desenvolvimento futuro dos modelos urbanos e também do próprio SIMRio. Pela primeira vez em toda sua trajetória, os modelos do LAURD são dimensionados por áreas, sendo que a unidade mínima é definida por um quadrado de $500 \mathrm{~m}$, ou 0,5km2, que evidentemente pode ser subdividido em função de demandas ocasionais. De qualquer modo, esta divisão garantirá um domínio mais rígido sobre o seu desenvolvimento, e permitirá que técnicas e métodos de trabalho com o motor gráfico possam ser testadas em áreas menores.

Uma nova área de estudo também deverá ser definida para testar todo o aprendizado técnico ganho com o trabalho realizado com o UDK. Assim, a pesquisa se voltará para o estudo dos espaços da Exposição do Centenário da 
Independência, ocorrida nas bordas do Morro do Castelo e a sua relação espacial com a cidade atual.

A escolha desse trecho de espaço e período de tempo para dar início a uma segunda fase de desenvolvimento do SIMRio, nos mesmos moldes conceituais da "viagem no tempo" da primeira fase, é motivada pelas recentes descobertas, durante pesquisas em acervos, de raras fotografias coloridas da exposição, feitas pelo fotógrafo Marc Ferrez, hoje pertencentes ao Instituto Moreira Salles, no Rio de Janeiro. Tais fotografias irão permitir o detalhamento do modelo do passado com a informação documental da cor dos edifícios, o que gera um grande interesse de pesquisa para ser desenvolvido. Além disso, espera-se que a relativa simplicidade estilística dos antigos pavilhões da Exposição, bem como a pouca densidade de ocupação dos seus espaços, permitirão testar métodos de desenvolvimento no motor gráfico com mais facilidade.

\section{Conclusões}

Traçou-se aqui a trajetória de desenvolvimento do simulador urbano digital SIMRio. Esta sistematização era uma tarefa devida há algum tempo, necessária e fundamental para preparar o caminho para os próximos passos. São ideias que necessitam ser amadurecidas, mas que aqui não se esgotam. Somente se organizam.

Após trilharmos todo o caminho que levou a pesquisa até seu estado atual, podemos afirmar que o simulador urbano SIMRio está voltado, fundamentalmente, para o próximo passo da representação gráfica digital, representado pela popularização das tecnologias de Realidade Virtual, que deve começar a ficar disponível a partir do ano de 2016. A chegada prometida de uma série de equipamentos relacionados a ela, tais como o Óculus Rift, Project Morpheus, HTC Vive, entre outros, representam uma nova geração de óculos de realidade virtual, que prometem sua popularização em âmbito doméstico, depois de muitas tentativas fracassadas ao longo dos anos, em função de limitações tecnológicas.

Além dos óculos, outros sistemas complementares, que permitem o movimento do usuário (em última análise, a inserção do seu corpo) no espaço digital - tais como a esteira multidirecional Virtuix Omni, ou ainda o protótipo Cyberith Virtualizer, entre vários outros produtos que vão na mesma direção - irão levar a representação digital do espaço para outros patamares qualitativos. Será o momento em que a representação irá romper os limites da tela do computador, e alcançará finalmente o corpo (e a mente) do usuário.

Para experiências que lidam com a reconstrução digital da história da cidade, como o SIMRio, as possibilidades são enormes e estimulantes. Será a possibilidade de visitar "corporalmente" a cidade do passado, experimentar sua escala e seus espaços, entender sua transformação no tempo de um modo inteiramente novo.

Nesse sentido, o futuro mal começou.

\section{Agradecimentos}

O autor gostaria de agradecer aos alunos de Iniciação Científica que estiveram sob sua orientação e participaram do desenvolvimento da primeira etapa do SIMRio desde seus antecedentes. Sem o seu engajamento, as complexas tarefas necessárias à sua construção não teriam sido realizadas, e os protótipos não seriam hoje uma realidade.

Esperamos que essa experiência tenha sido proveitosa em sua trajetória acadêmica, e que o aprendizado sobre a história do Rio de Janeiro, bem como sobre os processos de trabalho relacionados com a pesquisa histórica e com a Gráfica Digital, tenham contribuído para para sua formação como melhores arquitetos e urbanistas.

Portanto, um muito obrigado aos alunos Raphael Câmara Pinheiro (por seu entusiasmo com os videogames), Ana Beatriz Bruno, Andrea Baran, Arthur Naresi, Bianca Casale, Caroline Entrielli, Débora Mitsue, Jonas Abreu, Jorge Vinícius Silva, Juliete Reichert, Karina Comissanha, Luísa Teixeira, Maria Elisa Vianna, Marinah Raposo, Rodrigo d'Avila, Vanessa Bosi, Vanessa Rodrigues e Yuri Rosenthal.

\section{Referências}

Andreatta, Verena (2008). Atlas dos Planos Urbanísticos do Rio de Janeiro: de Beaurepaire-Rohan ao Plano Estratégico. Rio de Janeiro: ViverCidades.

Boron, Dariusz Jacob (2007). A Short History of Digital Gamespace. In: Von Borries, Friedrich; Walz, Stefen; Bottger, Matthias (Ed.) (2007). Space Time Play. Computer Games, Architecture and Urbanism: The Next Level. Boston: Birkhäuser.

Bueno, Raul (2013). Globos Virtuais e Cidade: Leituras Gráficas sobre a História do Morro de Santo Antônio no Rio de Janeiro. Dissertação de Mestrado. Rio de Janeiro: PROURB.

Canabrava, Eduardo (1964). Atlas da Evolução Histórica do Rio de Janeiro: Rio de Janeiro: Instituto Histórico e Geográfico Brasileiro (IHGB).

Chartier, Roger (1990). A História Cultural: Entre Práticas e Representações. Lisboa: DIFEL.

Dollens, Dennis (2002). De lo Digital a lo Analógico. Barcelona: Gustavo Gilli.

Jornada de Iniciação Científica (2010). Livro de Resumos da XXXII Jornada Giulio Massarani de Iniciação Científica, Artística e Cultural. Rio de Janeiro: Universidade Federal do Rio de Janeiro.

Jornada de Iniciação Científica (2013). Livro de Resumos da XXXV Jornada Giulio Massarani de Iniciação Científica, Artística e Cultural. Rio de Janeiro: Universidade Federal do Rio de Janeiro.

Kós, José Ripper (2001). Modeling the City History. In: Anais do 19th ECAADE Conference. Helsink.

Kós, José Ripper; Paraízo, Rodrigo Cury (2007). El Modelo de La Habana: Aproximaciones a la Modelización Urbana. 
In: Barros, Diana Rodrigues (Ed.). Urbamedia: Base de datos urbanos de areas centrales, casos de ciudades argentinas y latinoamericanas. Buenos Aires: Universidad de Buenos Aires. Paraízo, Rodrigo Cury (2014). A Representação das Cidades em Jogos Eletrônicos. III ENANPARQ: Arquitetura, Cidade e Projeto: Uma Construção Coletiva. Anais. In: III Encontro da Associação Nacional de Pesquisa e Pós-Graduação em Arquitetura e Urbanismo. São Paulo: Universidade Presbiteriana Mackenzie.

Segre, Roberto (2010). La Gráfica Digital como Instrumento de Investigación en la Historiografia UrbanoArquitectónica. In: Arquitectura y Urbanismo. Revista de la Facultad de Arquitectura de La Habana. Vol. 31. No. 1. La Habana: Cujae.

Segre, Roberto e Vilas Boas, Naylor (2011). Os Projetos de Alinhamento da Prefeitura do Distrito Federal (1900-1930): Uma História Oculta do Morro de Santo Antônio no Centro do Rio de Janeiro. In: Anais do 2o. Seminário Ibero-Americano Arquitetura e Documentação. Belo Horizonte.

Segre, Roberto; Koatz, Gilson e Vilas Boas, Naylor (2012a). The Center of Rio de Janeiro: Urban Cultural Paradoxes. In: Anais do 15th IPHS Conference - International Planning History Society. São Paulo: FAUUSP.

Segre, Roberto; Barki, José; Vilas Boas, Naylor e Leitão, Thiago (2012b). Rio de Janeiro: Monumentality and Transfiguration of a Lost Capital-City. In: Anais do 15th IPHS Conference International Planning History Society. São Paulo: FAUUSP.
Segre, Roberto (2013). Ministério da Educação e Saúde: Ícone Urbano da Modernidade Brasileira. São Paulo: Romano Guerra Editora.

Sillos, Jacques (2015). Largo da Misericórdia: Marcos da Fundação do Rio de Janeiro (1565-2015). Rio de Janeiro: Andrea Jakobsson Estudio.

Till, Joy Helena Worms (2014). Paisagem Gráfica da Cidade: Um Olhar sobre o Rio de Janeiro. Tese de Doutorado. Rio de Janeiro: PROURB.

Vilas Boas, Naylor (2005). Além da Imagem Estática: A Representação Gráfica Digital da Experiência Espacial na Arquitetura. In: Visión y Visualización. IX Congresso IberoAmericano de Gráfica Digital (Sigradi). Anais. Lima: Universidad Peruana de Ciências Aplicadas (UPC).

Vilas Boas, Naylor (2007). A Esplanada do Castelo: Fragmentos de uma História Urbana. Tese de Doutorado. Rio de Janeiro: PROURB/FAU/UFRJ.

Vilas Boas, Naylor (2010). A Construção de Cidades Digitais: Desafios e Estratégias Metodológicas In: Machado, Denise P. et al. (org.). I Encontro Nacional de Pós-Graduação e Pesquisa em Arquitetura e Urbanismo. Anais. Rio de Janeiro: PROURB.

Von Borries, Friedrich; Walz, Stefen; Bottger, Matthias (Ed.) (2007). Space Time Play. Computer Games, Architecture and Urbanism: The Next Level. Boston: Birkhäuser.

Werthein, Margaret (2001). Uma História do Espaço: de Dante à Internet. Rio de Janeiro: Jorge Zahar. 